Jurnal Ilmu Komunikasi UHO : Jurnal Penelitian Kajian Ilmu Komunikasi dan Informasi.

Volume 6, No. 4, Oktober 2021, hlm 525-547

\title{
REPRESENTASI GENDER BENDING DALAM MUSIK POPULER (ANALISIS SEMIOTIKA PADA MUSIK VIDEO TAYLOR SWIFT - YOU NEED TO CALM DOWN)
}

\author{
Restu Maulia $^{1}$, Nurul Fauziah ${ }^{2}$ \\ Universitas Bhayangkara Jakarta Raya \\ J1. Raya Perjuangan, Bekasi, Jawa Barat, 17121, Indonesia
}

\begin{abstract}
ABSTRAK
Musik video sebagai produk budaya popular mampu membangun intepretasi penonton terhadap objek yang dilihatnya. Seperti pada musik video Taylor Swift berjudul "You need to calm down", yang dominan menggunakan simbol dari pengabaian identitas gender yang penulis sebut dengan gender bending. Penelitian ini bertujuan untuk menganalisa representasi Gender Bending pada musik populer dalam musik video Taylor Swift You Need to Calm Down. Menggunakan analisis semiotika lima kode Roland Barthes, penelitian ini berupaya untuk mengungkap dan menganalisa representasi dari gender bending yang ditampilkan dalam musik video. Hasil analisa semiologi kode Roland Barthes, penelitian ini menemukan adanya representasi gender bending sebagai sebuah simbol budaya popular yang digambarkan melalui fashion, ide, sikap, bahasa dan perilaku dalam adegan-adegan video. Gender bending juga direpresentasikan sebagai sebuah perjuangan kesetaraan hak untuk dapat diterima dan diakui keberadaannya sebagai bagian dari perkembangan sistem sosial dari masyarakat barat saat ini.
\end{abstract}

Kata-kata Kunci: Budaya Populer; Gender Bending; Representasi; Semiotika 
Jurnal Ilmu Komunikasi UHO : Jurnal Penelitian Kajian Ilmu Komunikasi dan Informasi.

Volume 6, No. 4, Oktober 2021, hlm 525-547

\title{
GENDER-BENDING REPRESENTATION IN POPULAR MUSIC (SEMIOTICS ANALYSIS OF TAYLOR SWIFT MUSIC VIDEO - YOU NEED TO CALM DOWN)
}

\begin{abstract}
Music video as a product of popular culture is able to build the audience's interpretation of the object they see. As in Taylor Swift's music video entitled "You need to calm down", which dominantly uses a symbol of neglecting gender identity which the writer calls gender bending. This study aims to analyze the representation of gender bending in popular music in Taylor Swift's music video, you need to calm down. Using a semiotic analysis of Roland Barthes' five codes, this study seeks to uncover and analyze the representation of gender bending that is displayed in the music video. The results of the semiological analysis of Roland Barthes' code, this study found a representation of gender bending as a symbol of popular culture depicted through fashion, ideas, attitudes, language and behavior in video scenes. Gender bending is also represented as a struggle for equality of rights to be accepted and recognized as part of the development of the social system of western society today.
\end{abstract}

Keyword: Populer Culture; Gender bending; Representation; Semiotics 
Jurnal Ilmu Komunikasi UHO : Jurnal Penelitian Kajian Ilmu Komunikasi dan Informasi.

Volume 6, No. 4, Oktober 2021, hlm 525-547

\section{PENDAHULUAN}

Sejarah narasi kesetaraan gender di Amerika Serikat dimulai saat momentum Amandemen Ke-19 Konstitusi Amerika Serikat tahun 1919, saat pengakuan terhadap hak politik untuk kaum perempuan di Amerika disuarakan. (Adamson, 2008) Isu keseteraaan gender kemudian terus berkembang di Amerika, dan gerakannya mewarnai perjalanan musik yang mengangkat isu keseteraan gender diera 1960-an. Era ini sering disebut sebagai era lahirnya kembali musik rakyat dan gerakan sipil, termasuk gerakan feminis. (Lubis, 2006)

Pembahasan tentang gender memang belum menemukan satu konstruksi definisi yang baku. Terminologi gender sendiri memiliki banyak perspektif pengertian dan konsepsinya. Setyorini dalam penelitiannya melihat gender sebagai sebuah proses duplikasi yang selalu berulang. Maskulinitas atau femininitas hanyalah sebuah ide yang terus diyakini masyarakat sebagai sebuah simbol dari menjadi seorang laki-laki ataupun perempuan. (Ari Setyorini, 2011)

Pada perspektif seksual, Yuliani dalam penelitiannnya mencontohkan pandangan masyarakat terkait dua orang berbeda jenis kelamin yang saling memiliki ketertarikan dan rasa cinta adalah sesuatu yang umum dan harus demikian adanya. (Indana Laazulva, Yuli Rustinawati, 2013) Konsekuensinya, ketika terdapat hubungan emosional dan seksual diantara sesama jenis akan dianggap sebagai sesuatu yang salah, tidak normal dan menabrak nilai budaya serta agama. Sayangnnya, padangan ini diperkuat dan dipertahankan oleh negara melalui sistem dan aturan hukum. Akibatnya, muncul stigmatisasi dan diskriminasi pada manusia yang dianggap berbeda.

Sementara itu, seperti disebutkan oleh Haryati dalam penelitiannya bahwa media massa, melalui budaya popular, dianggap berhasil mengkonstruksi makna gender yang justru menyajikan perjuangan gender yang menurunkan nilai kemurniannya. (Haryati, 2012) Padahal, intensitas media massa yang terus-menerus, mampu mengarahkan perilaku pengguna media untuk mengikuti hingga lebih jauh mengadopsi setiap apa yang dipublikasikan media massa. (Strinati, 2010)

Gender bending sendiri merupakan bentuk aktivisme sosial yang dilakukan untuk menanggapi asumsi atau pengabaian jenis kelamin. Gender bending adalah istilah yang digunakan untuk merujuk kepada orang yang secara aktif melanggar aturan gender (transgresses), atau "berbelok" dari peran gender yang diharapkan. (Dese, 2013) Pelaku gender bending dapat mengidentifikasi diri mereka sebagai transgender dan gender queer, 
Jurnal Ilmu Komunikasi UHO : Jurnal Penelitian Kajian Ilmu Komunikasi dan Informasi.

Volume 6, No. 4, Oktober 2021, hlm 525-547

yaitu orang-orang dengan orientasi homoseksual. Gender bending, terus berkembang sebagai realitas yang terfasilitasi oleh budaya popular yang menangkap fenomena kelahiran kelompok LGBT sebagai simbol dari gender bending.

Para aktivis gender bending memanfaatkan budaya popular untuk mengkampanyekan ide dan kelompoknya, salah satunya adalah video musik. Salah satu musik video yang sarat dengan konsep gender bending adalah video klip You Need to Calm Down dari musisi Amerika Taylor Swift. Taylor Swift yang dikenal sebagai bagian dari ikon budaya pop abad 21 pernah menyatakan dirinya sebagai feminis pada tahun 2014.

Dilansir dari Tirto.id, sejak awal video musik You Need to Calm Down di luncurkan pada tanggal 17 Juni 2019, fokus untuk menyampaikan pesan dukungan Taylor Swift terhadap LGBT. (Samudro, 2019) Dalam video klipnya, Taylor Swift beserta sebagian teman selebritasnya digambarkan sebagai pendukung LGBT yang santai dalam menanggapi protes kelompok anti LGBT. Protes ini digambarkan dengan menggunakan atribut yang penuh kebencian terhadap LGBT yang diperankan oleh Taylor Swift beserta artis-artis dan pemeran pendukung dalam musik videonya yang tak satupun laki-laki divisualkan normal pada umumnya masyarakat memandang. (Damaledo, 2019), (Adryamarthanino, 2020)

Penelitian ini tertarik untuk menganalisa representasi gender bending pada musik video Taylor Swift yang berjudul You Need to Calm Down tersebut. Melalui analisis lima kode dari Rolanda Barthes, penelitian ini akan mengungkap bagaimana respresentasi gender bending dalam musik video. Representasi menjelaskan bagaimana orang lain menangkap pesan dalam objek yang dikomunikasikan. Melalui analisis lima kode dari Rolanda Barthes, penelitian ini ingin mengungkapkan bagaimana representasi gender bending dalam musik video You Need to Calm Down, Taylor Swift yang menampilkan seluruh talent dari kalangan gay, dan transgender.

\section{METODE PENELITIAN}

Penelitian ini menggunakan pendekatan kualitatif dengan paradigma konstruktivis. Menggunakan analisis semiotika Roland Barthes, penelitian ini mencoba melihat realitas signifikannya objek, yaitu mengungkapan makna semiotik Bending Gender yang direpresentasikan dalam video musik You Need to Calm Down milik Taylor Swift). Mudjiyanto menyebutkan semiotika Roland Barthes bertujuan untuk menyediakan metode analisis dan kerangka berpikir untuk menghindari terjadinya misreading pembacaan atas 
Jurnal Ilmu Komunikasi UHO : Jurnal Penelitian Kajian Ilmu Komunikasi dan Informasi.

Volume 6, No. 4, Oktober 2021, hlm 525-547

makna suatu tanda. (Bambang Mudjiyanto, 2013) Baginya, prinsip dari semiotika dalah pemaknaan dan penafsiran atas tanda.

Vither menyebutkan, analisis semiotika memiliki beberapa tahap pembongkaran makna sebelum akhirnya gagasan dominan terkuak, yaitu menggunakan analisis sintakmatik dan paradigmatik. (Brillian Barro Vither, 2015) Fiske menjelaskan, level pertama, yakni: realitas/ reality (penampilan/ apprearance, kostum/ dress, tata rias/ make up, lingkungan/ environment, bahasa tubuh/ gesture, gaya berbicara/ speech, dan ekspresi/ expression). Level kedua yakni representasi/ representation (kamera/ camera, pencahayaan/ lighting, musik/ music) yang selanjutnya ditransmisikan ke dalam konflik, karakter, dialog, dan lain-lain. Dua kode tersebut selanjutnya akan dikenal dengan analisis sintagmatik. (Brillian Barro Vither, 2015) Pada penelitian ini, pengungkapan kode adalah bagaimana representasi gender bending yang ditampilkan dan dimaknakan dalam musik video Taylor Swift "You Need To Calm Down".

Dalam prosesnya analisis data untuk mengungkap dan menganalisa representasi gender bending dalam musik video tersebut, peneliti menggunakan tahapan analisis data sintagmatik untuk mendeskripsikan apa saja representasi gender bending yang ada dalam musik video, kemudian analisis semiologi lima kode Barthes untuk menganalisa bagaimana representasi gender bending ditampailkan dalam musik video.

\section{HASIL DAN PEMBAHASAN}

Penggambaran kesetaraan gender yang sejatinya terfokus pada kesamaan hak, kesetaraan kesempatan dan pembudayaan apresiasi terhadap keberadaan perempuan tidak hanya dilihat sebagai teks jenis kelamin semata. Kesetaraan gender terus berkembang dan meluas, namun juga semakin kehilangan maknanya.

Media massa dianggap berhasil mengkonstruksi pembiasan makna tersebut melalui budaya popular yang justru menyajikan perjuangan gender yang menurunkan nilai kemurniannya. (Hanif, 2011) Menurutnnya, kebudayaan populer adalah produk kebudayaan yang diproduksi oleh media massa atas kepentingan kapitali. Intensitasnya yang terusmenerus dalam menyajikan semakin memperkuat biasnya makna gender.

Gender bending sebagai aktivisme sosial dalam mereduksi konstruksi sosial atas pemisahan gender, khususnya terkait jenis kelamin yang tidak konsisten. Gender bending menurut Brian Sloan adalah istilah yang digunakan untuk merujuk kepada orang yang secara 
Jurnal Ilmu Komunikasi UHO : Jurnal Penelitian Kajian Ilmu Komunikasi dan Informasi.

Volume 6, No. 4, Oktober 2021, hlm 525-547

aktif melanggar aturan gender (transgresses), atau "berbelok" dari peran gender yang diharapkan. (Dese, 2013) Gender bending atau pembengkokan gender adalah apabila seseorang menunjukan keartifisialan dari sifat maskulinitas dan feminitas secara berlawanan, seperti yang dilakukan oleh androgini dengan cara menggunakan identitas peranan seks yang berlawanan. (Piliang, 2012)

Para aktivis gender bending memanfaatkan budaya popular untuk mengkampanyekan ide dan kelompoknya, salah satunya melalui musik video. Menurut Moller video klip atau musik video adalah sebuah film pendek atau video yang mendampingi alunan musik, umumnya sebuah lagu, video klip atau musik video modern berfungsi sebagai alat pemasaran untuk mempromosikan sebuah album rekaman. (Moller, 2011)

Musik video merupakan media yang sangat tepat untuk membuat stereotip dibanding lirik. (Douglas Kellner, 2010) Sebab, video musik dianggap memberikan penanda secara bebas dan tidak mengatur pada satu totalitas makna saja. Akhirnya, video musik menjadi gerbang 'apik' bagi para aktivisme gender bending untuk mempublikasikan kelompoknya. Hal yang diperlukan dalam pembuatan musik video agar pesan dalam lirik lagu dipahami dan diterima adalah konsep yang matang, baik dari segi konsep alur cerita serta penempatan objek. (Muslim, 2021)

Musik video You Need to Calm Down dirilis pada 14 Agustus 2019 sebagai salah satu bentuk menyuarakan dukungannya terhadap komunitas LGBT. Musik video yang dibawakan oleh Taylor Swift dan disutradarai oleh Drew Kirsch ini berdurasi 03:30 detik. Sejak awal video, musik video You Need to Calm Down dari Taylor Swift penonton disuguhkan adeganadegan yang diisi oleh para talent dan cameo yang berlatar belakang dari kalangan LGBT. Properti yang digunakan dalam video juga menyimpan berbagai cerita dan makna yang dikemas dalam narasi singkat kehidupan para LGBT di sebuah pemukiman trailer yang bernuansa pelangi. Selain menggunakan talent sebagai cameo.

Seperti disebutkan, proses mernahami tanda yang disebut Barthes sebagai signifikansi atau semiosis adalah proses untuk menafsirkan dan menguraikan tanda beserta kode, sehingga diperoleh makna yang tersimpan di balik sistem pertandaan. (Bambang Mudjiyanto, 2013) Terdapat 3 hal yang dipertimbangkan dalam penafsiran tanda, yaitu visual pembentuk tanda (warna, ukuran, ruang, kontras, bentuk, kehalusan tekstur/ grain, teknis pembentuk tanda ('cara' menampilkan memvisualisasin makna dan ideologi ke dalam bentuk desain 
Jurnal Ilmu Komunikasi UHO : Jurnal Penelitian Kajian Ilmu Komunikasi dan Informasi.

Volume 6, No. 4, Oktober 2021, hlm 525-547

grafis), dan perilaku pembentuk tanda (setiap gerakan yang dimaksud untuk mengirimkan tanda visual).

\section{Talent Musik Video You Need to Calm Down}

Pada musik video ini, Taylor Swift menggunakan 29 talent sebagai cameo dalam videonya. Mulai dari model terkenal Dexter Mayfield yang merupakan seorang queer. Queer menurut Rokhmansyah (2016:28) merujuk pada kelompok yang memiliki orientasi seksual diluar heteroseksual. Juga Ellen DeGeneres, Hayley Kiyoko dan Hannah Hart yang secara terbuka menyatakan diri sebagai lesbian. Adam Lambert, Adam Rippon, Chaster Lockhart, Todrick Hall, Tyler Ferguson dan Justin Mikita yang juga menyatakan diri sebagai gay, Billy Porter, dan RuPaul Queer Eye yang merupakan transgender.

Representasi gender dalam media diwujudkan dalam tiga bentuk, yaitu identitas gender, peran gender, dan status gender. (Hamidah, 2017). Menurutnya, identitas gender meliputi empat elemen, yakni sifat dan perilaku, jenis permainan, ambisi dan minat, serta pencapaian. Meskipun ketiga hal tersebut mengandung missrepresentasi marginalisasi. Berikut adalah representasi talent musik video You Need to Calm Down:

\section{Analisis Sintagmatik dan Paradigmatik}

Analisis semiotika memiliki beberapa tahap pembongkaran makna sebelum akhirnya gagasan dominan terkuak, yaitu menggunakan analisis sintagmatik dan paradigmatik. (Brillian Barro Vither, 2015)

Analisis Sintagmatik

Analisis data sintagmatik dilakukan dengan mendeskripsikan penampilan (apprearance), kostum (dress), dan tata rias (make up) para talent dalam musik video. Kemudian lingkungan (environment) dari pengambilan gambar, bahasa tubuh (gesture) dan gaya berbicara (speech), hingga ekspresi (expression) dari para talent, selanjutnya melalui pengambilan frame kamera dan musik. (Chasanah, 2017) 
Jurnal Ilmu Komunikasi UHO : Jurnal Penelitian Kajian Ilmu Komunikasi dan Informasi.

Volume 6, No. 4, Oktober 2021, hlm 525-547

1. Analisis Sintagmatik Scene Awal

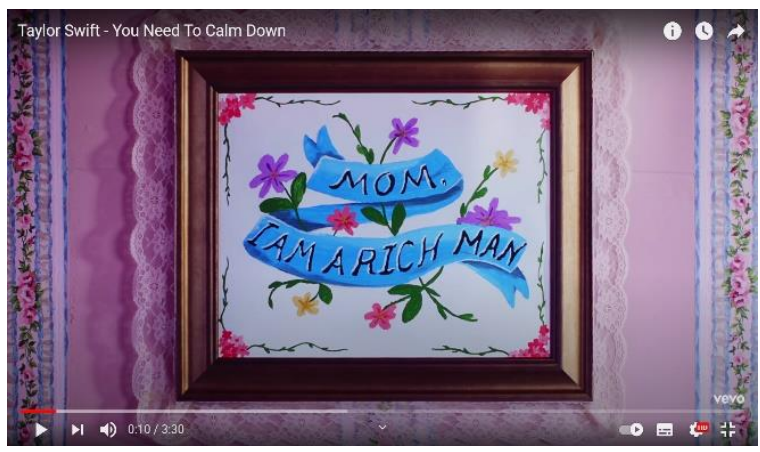

Gambar 20. Sequence 00:08 - 00:26

Narasi yang dibangun dalam adegan ini adalah terdapat sebuah kutipan dengan tulisan di dalam sebuah bingkai berbunyi "Mom. I Am A Rich Man." yang dipajang pada dinding dengan motif bunga-bunga dan dinding yang bercorak warna pink. Pengambilan gambar pada adegan ini dilakukan secara closeup.

2. Analisis Sintagmantik Scene Pernikahan

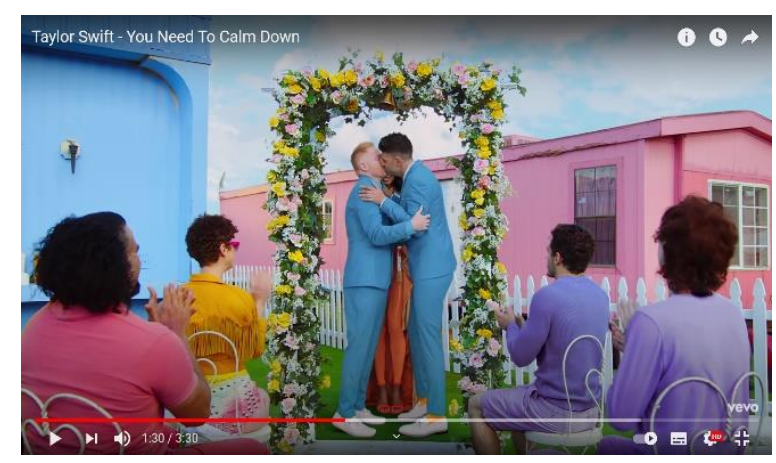

Gambar 21. Sequence 01:29-01:34

Narasi yang terlihat dalam adegan ini adalah upacara pernikahan dua orang pria, pada altar pernikahan dengan ornamen bunga-bunga. Pada acara pernikahan tersebut tampak dihadiri oleh beberapa orang lainnya. Penggunaan warna-warna cerah pada atribut para pemeran dan berbagai ornamen adegan cukup mencolok pada adegan ini. Pengambilan gambar dalam adegan adalah total shot dengan frame kamera seluruh bagian dari pasangan yang sedang menikah. 
Jurnal Ilmu Komunikasi UHO : Jurnal Penelitian Kajian Ilmu Komunikasi dan Informasi.

Volume 6, No. 4, Oktober 2021, hlm 525-547

3. Analisis Sintagmatik Scene Protes Warga
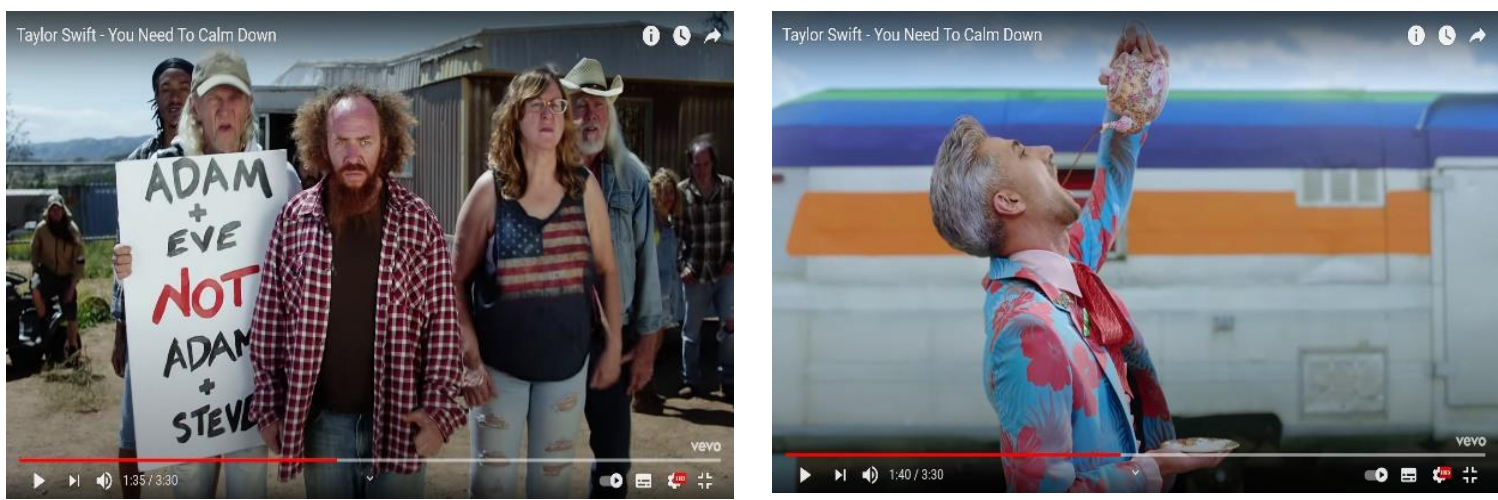

Gambar 22. Sequence 01:35-01:40

Narasi yang dibangun dalam adegan adalah adanya sekelompok orang yang tampak sedang melakukan protes, menggunakan poster bertuliskan sindiran satir. Adegan sekelompok orang yang sedang protes tersebut muncul setelah adegan pernikahan pada leksia sebelumnya. Kemudian adegan berikutnya adalah seorang pria yang sedang berjalan sambil meminum air dalam sebuah teko kecil, setelah meminum memberikan pria tersebut melanjutkan berjalan sambil tersenyum ke kamera.

Dari settingnya, tampak kelompok orang-orang yang seperti melakukan protes dengan seorang pria yang minum air sambil berjalan memiliki gaya berpekaian dan berpenampilan yang sangat jauh berbeda, baik gaya berjalan maupun pakaian dan asesoris yang dikenakan. Pengambilan gambar pada adegan ini adalah medium shot untuk memperdekat jarak gambar menunjukan detail gerakan yang dilakukan para talent.

4. Analisis Sintagmatik Scene Pria Penjual Eskrim

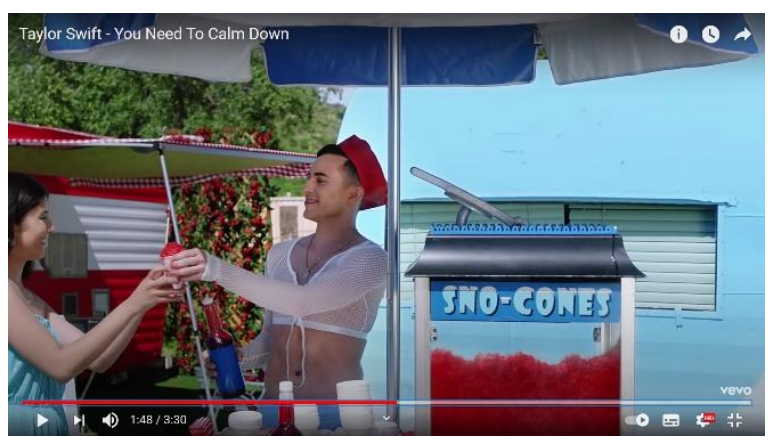

Gambar 23. Sequence 01:46-01:49 
Jurnal Ilmu Komunikasi UHO : Jurnal Penelitian Kajian Ilmu Komunikasi dan Informasi.

Volume 6, No. 4, Oktober 2021, hlm 525-547

Narasi yang dibangun dalam adegan ini adalah seorang pria yang sedang menjajakan es krim berbentuk cone, kepada dua orang pembeli. Pengambilan gambar dalam adegan ini adalah close up yang menunjukan detail wajah dan atribut dari pria penjual eskrim.

5. Analisis Sintagmatik Scene Panggung "Pop Queen Pageant"

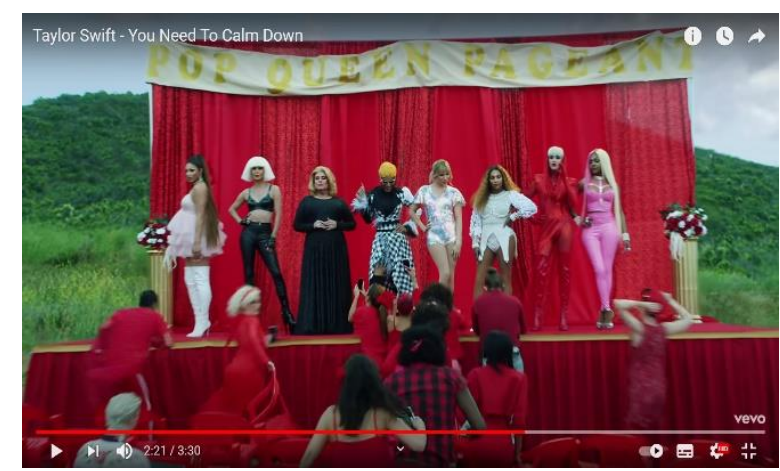

Gambar 24. Sequence 02:21 - 02:38

Narasi yang dibangun dalam adegan ini adalah sebuah panggung seperti ajang pencarian bakat, yang dapat dilihat dari sebuah poster besar di atas panggung bertuliskan "Pop Queen Pageant". Di atas panggung tampak berdiri berjajar para waria dengan pakaian dan gaya tubuh yang menyerupai para penyanyi pop terkenal di Amerika.

6. Analisis Sintagmatik Scene Pelemparan Mahkota
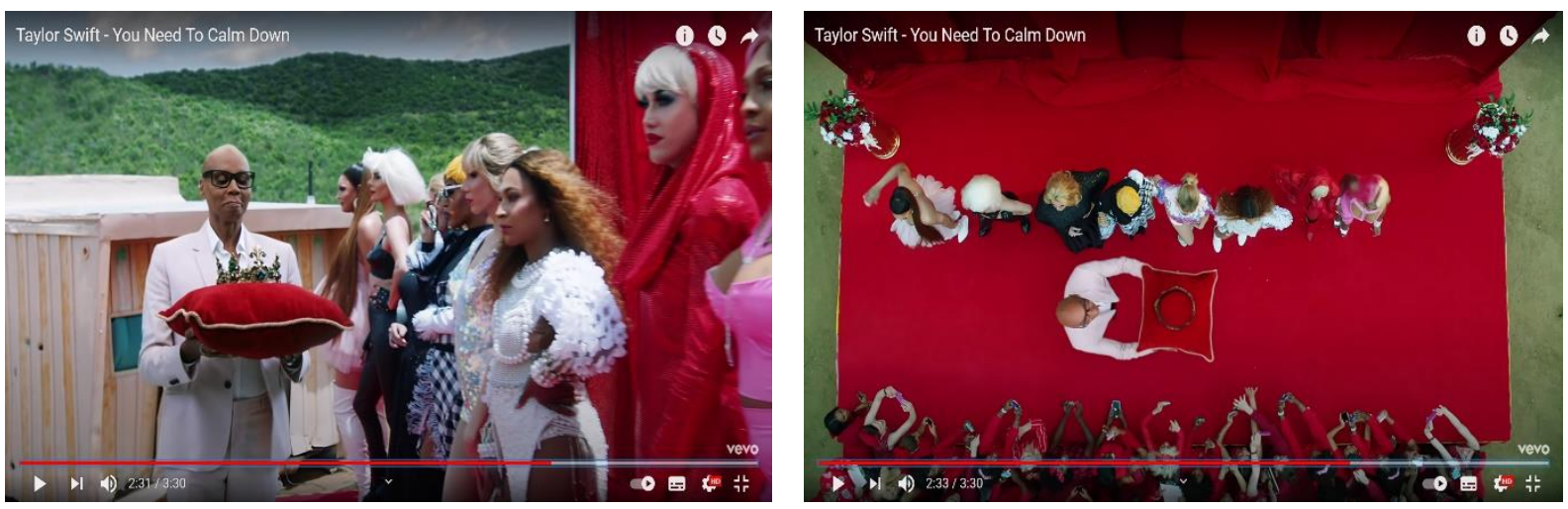

Gambar 25. Sequence 02:21-02:38

Narasi yang dibangun dalam adegan ini, merupakan kelanjutan dari adegan sebelumnya para waria yang sedang berdiri di atas sebuah panggung "Pop Queen Pageant". Pada adegan ini seseorang tampak naik ke atas panggung dengan membawa sebuah mahkota, kemudian mahkota tersebut dilemparkan ke udara. 
Jurnal Ilmu Komunikasi UHO : Jurnal Penelitian Kajian Ilmu Komunikasi dan Informasi.

Volume 6, No. 4, Oktober 2021, hlm 525-547

7. Analisis Sintagmatik Scene Lukisan
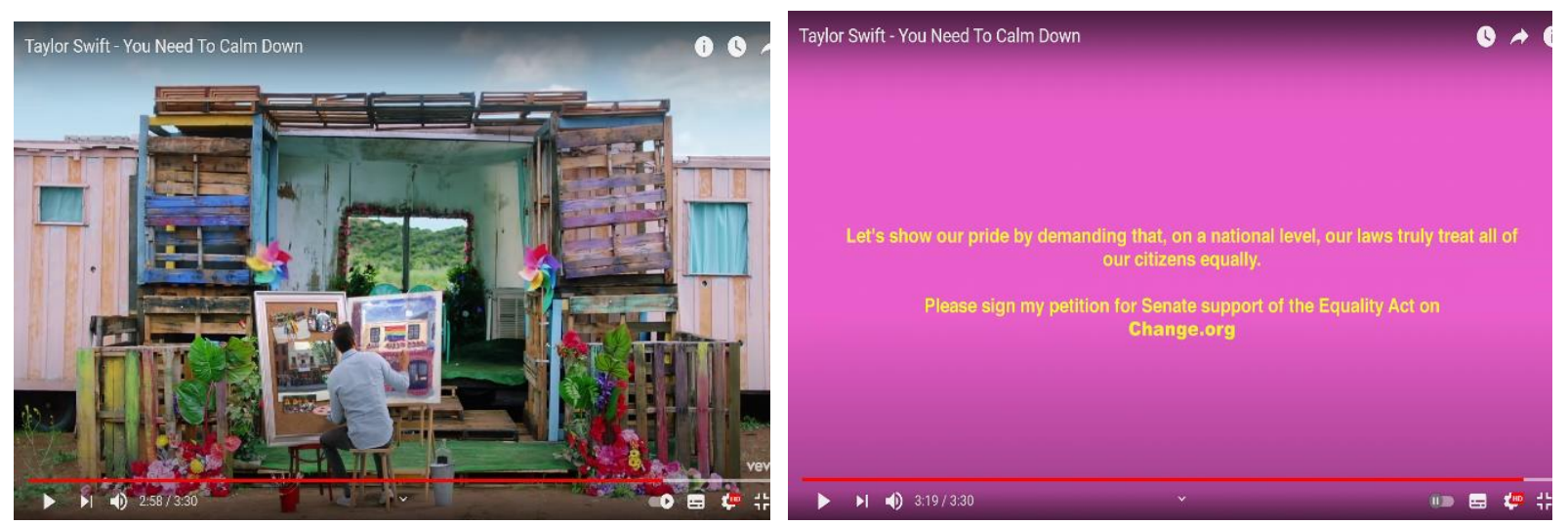

Gambar 26. Sequence 02:21 - 02:38

Narasi yang dibangun dalam adegan ini adalah seorang pria yang sedang melakukan kegiatan melukis pada sebuah kanvas, dengan objek lukisan adalah sebuah foto dan ruangan kosong. Tampak beberapa bunga yang diletakkan pada bagian depan bangunan. Selanjutnya adalah narasi penutup video dengan menampilak sebuah petisi yang berbunyi sebuah dukungan untuk equality atau kesetaraan sebagai credit title video.

Pengambilan gambar dalam adegan ini adalah over shoulder atau pengambilan dari belakang bagian tubuh seseorang, sehingga dapat diketahui seorang pris yang sedang melukis. Kemudian frame dengan medium shot yang menampilkan sebuah petisi dukungan sebagai penutup video.

\section{Analisis Paradigmatik}

Analisis paradigmatik dilakuikan dengan menganalisis 5 (llima) kode Barthes, yaitu: hermeneutik, proaretik, simbolik, kultural, dan semantik. Awalnya, semiologi lima kode dari teori semiotika Roland Barthespada digunakan untuk menganalisis signifikansi ideologi dalam budaya kontemporer yang berlaku pada masa hidupnya saat itu di Perancis. (Sobur, 2013) Menurutnya, ideologi ada selama kebudayaan masih ada Kebudayaan mewujudkan dirinya ke dalam teks-teks, dengan demikian ideologi mewujudkan dirinya melalui berbagai kode yang merembes masuk ke dalam teks dalam bentuk penanda penting, seperti tokoh, latar, sudut pandang, dan sebagainya. 
Jurnal Ilmu Komunikasi UHO : Jurnal Penelitian Kajian Ilmu Komunikasi dan Informasi.

Volume 6, No. 4, Oktober 2021, hlm 525-547

1. Analisis Paradigmatik Scene Awal

Pada leksia ini ada beberapa enigma atau teka-teki yang dapat disingkapkan terkait dengan makna hermeneutiknya. Ada pertanyaan yang ditawarkan pada adegan ini, "kenapa ada tulisan tersebut?" "apa hubungannya dengan musik?” Teka-teki tulisan dalam bingkai foto adalah kutipan dari ikon selebriti kesetaraan gender, Cherilyn Sarkisian, dalam wawancara di salah staisun televisi AS pada tahun 1996, seorang bintang yang menolak norma sosial tertentu dan memandang pria sebagai kemewahan seperti "makanan penutup." Dalam wawancara, Cher merefleksikan keinginan ibunya agar dia menetap dan menikah dengan "pria kaya." Namun tanggapan Cher kepada ibunya, "Saya berkata, 'Bu, saya lah orang kaya itu."

Analisis kode proaretik adalah kode aksi dan tindakan. Kode aksi yang dapat diketahui dari leksia ini, adalah aksi seorang Cher yang merupakan ikon pop feminis liberal yang menempatkan laki-laki tidak lebih dari jenis kelamin biologis semata, memiliki kedudukan yang setara dengan wanita dalam segi ekonomi dan sosial.

Analisis kode simbolik merupakan pengkodean yang lebih mudah untuk ditemukan karena penggunaan simbol-simbol yang dominan, baik secara teks, visual maupun ekspresi. Pada unit analisis ini, tulisan dalam bingkai pada dinding dari kutipan wawancara Cher, yang seorang pendukung ide feminisme menunjukan simbolisasi feminisme sebagai bagian dari konsepsi gender bending.

Analisis kode kultural sangat erat kaitannya dengan latar sosial-budaya yang ditunjukan melalui tanda-tanda secara tekstual dan visual. Pada leksia ini, terdapat kode kultural dari budaya feminisme yang divisualisasikan melalui sebuah kutipan pernyataan. Meskipun hanya sekilas, namun ide feminisme yang menempatkan perempuan tidak sebagai subordinat dari laki-laki menunjukan bagaimana budaya feminisme memiliki arah yang sama dengan konsepsi dari gender bending yang menolak untuk pengidentifikasian gender tertentu dalam kehidupan sosial maupun ekonomi.

Analisis kode semantik adalah kode yang memunculkan konotasi tertentu. Dalam adegan awal musik video ini terdapat pemaknaan yang terkait dengan kode semantik. Pemilihan kutipan pernyataan Cher yang dijadikan bingkai foto pada dinding, memperlihatkan bagaimana sikap politik dari seorang feminis yang menolak ketergantungan wanita pada pria dalam relasi ekonomi. Pernyataan Cher tersebut memiliki makna bahwa wanita sesungguhnya tidak membutuhkan laki-laki kaya untuk dapat menjadi seorang wanita 
Jurnal Ilmu Komunikasi UHO : Jurnal Penelitian Kajian Ilmu Komunikasi dan Informasi.

Volume 6, No. 4, Oktober 2021, hlm 525-547

kaya. Wanita tersebutlah yang harus mampu menjadi orang kaya dan mencintai laki-laki bukan karena membutuhkan hartanya, tetapi karena cintanya.

2. Analisis Paradigmatik Scene Kumpulan Karavan

Analisis kode hermeneutik pada leksia ini adalah menyajikan pertanyaan pada penonton, mengapa hanya mereka yang tinggal disitu? Apakah memang ada pemukiman yang khusus untuk mereka? Kenapa rumah mereka adalah sebuah mobil? Dalam scene-scene berikutnya ditunjukan bagaimana para pelaku gender bending membangun komunitas untuk mengekspresikan diri mereka yang jauh dari pemukiman masyarakat lokal. Dibuatnya latar khusus bagi para pelaku gender bending dalam musik video ini menunjukan adanya pesan khusus dari Taylor untuk memberikan ruang bagi para pelaku gender bending menunjukan eksistensi dan krativitas mereka dan jauh dari singgungan dengan masyarakat pada umumnya.

Analisis kode proaretik sebagai kode aksi dan tindakan, pada leksia ini adalah tindakan kehidupan secara berkelompok yang menjadi sebuah aksi kolektif dari para pelaku gender bending. Latar kehidupan berkelompok yang di dalamnya memberikan gambaran kehidupan dari komunitas gender bending dalam musik video Taylor Swift sangat erat bagaimana tindakan mereka untuk menciptakan dunianya sendiri. Ini sebagaimana di jelaskan oleh Baudrillard bahwa dalam perspektif budaya populer dan liberal, pemanfaatan media dalam produksi budaya populer adalah kedudukan media yang menyimulasikan situasi nyata, bukan untuk merepresentasikan dunia, tetapi untuk menciptakan suatu dunia tersendiri. (Rizki Kurniawan, 2014)

Analisis kode simbolik menggambarkan bagaimana kode-kode yang merujuk pada suatu simbol tertentu disampaikan. Pada leksia ini, gambaran pemukiman para gender bending dalam video adalah penggunaan komodifikasi yang erat dengan simbolisasi LGBT dan gerakan gender bending.

Analisis kode kultural yang menjadi latar dalam adegan ini adalah budaya para pelaku gender bending yang ditunjukan dengan menciptakan dunia mereka sendiri, sistem sosial kelompok sendiri, kemudian budaya yang dianut oleh kelompok mereka sendiri sebagai budaya yang mencerminkan keberadaan dari gender bending. Dijelaskan oleh Barthes, kode semik atau kode semantik merupakan konotasi yang memanfaatkan sebuah isyarat, petunjuk atau kilasan makna yang ditimbulkan oleh penanda-penanda tertentu. (Bambang Mudjiyanto, 2013) Konotasi kehidupan kolektif dari pelaku gender bending berdampingan, tanpa sekat, dan bebas menjalankan apapun sesuai dengan kebutuhan mereka. 
Jurnal Ilmu Komunikasi UHO : Jurnal Penelitian Kajian Ilmu Komunikasi dan Informasi.

Volume 6, No. 4, Oktober 2021, hlm 525-547

3. Analisis Paradigmatik Scene Pernikahan

Terkait dengan kode hermeneutik, pada adegan ini terdapat beberapa teka-teki untuk diungkapkan. Pertama, kenapa ada pernikahan pasangan gay? Apa hubungannya dengan musik ini? Pasangan gay dalam video ini adalah psangan gay Jesse Tyler Ferguson dan Justin Mikita, yang merupakan pasangan gay sesungguhnya dalam kehidupan nyata. Dalam musik video ini Taylor secara total membawa ide-ide gender bending dalam musiknya. Bagaimana kampanye kesetaraan hak, kebebasan dalam menentukan pilihan hidup, serta aspek hukum yang berkaitan dengan kehidupan para gender bending yakni pernikahan sesama jenis, yang dalam leksia ini adegan tersbeut diperankan secara langsung oleh pasangan gay dalam kehidupan nyata untuk mendapatkan nilai lebih dalam mengkampanyekan gender bending.

Analisis kode proaretik dalam leksia ini adalah dilaksanakan pernikahan gay yang dihadiri oleh anggota kelompok dari komunitas mereka sendiri. Aksi pernikahan pasangan gay dalam video ini menunjukan bagaimana legalitas bagi keberlangsungan gerakan gender bending, yang menginginkan pengakuan dalam kehidupan seksual dan lembaga pernikahan.

Analisis kode simbolik yang dapat diamati dalam adegan ini adalah pernikahan pasangan gay sebagai smbolisasi dari gender bending itu sendiri. Dalam studinya mengenai konstruksi sosial pernikahan gay Siahaan menyebutkan terdapat dua bentuk hubungan dalam kehidupan para pelaku pasangan sesama jenis, yakni Open Relationship dan Closed Relationship. (Jokie M.S. Siahaan, 2009) Open Relationship adalah hubungan sesama jenis yang dilakukan secara terang-terangan di hadapan publik. Sementara, Closed Relationship merupakan kebalikannya cenderung disembunnyikan. Pada adegan ini simbol pasangan gay Closed Relationship ditayangkan untuk menunjukan simbolisasi kultur dan sosial dari gender bending.

Analisis kode kultural yang tampak dalam leksia ini adalah kultur pernihakan sesama jenis yang menjadi bagian dari konsepsi gender bending. Bagi masyarakat secara khusus yang memiliki konstruksi kebudayaan timur, keyakinan dan agama, pernikahan merupakan simbol sakral dalam kehidupan masyarakat. Sebab, menurut Siahaan pernikahan tidak hanya dalam konteks penyatuan dua insan yang saling mencintai secara sah, tetapi juga untuk menghindari adanya konflik yang berkaitan dengan larangan agama dan adat istiadat tertentu. (Jokie M.S. Siahaan, 2009)

Analisis kode semantik dalam adegan ini adalah pernikahan sesama jenis yang diperankan oleh adegan pasangan gay asli dalam kehidupan nyatanya. Pemaknaan terhadap lembaga perkawainan sebagai salah satu dari kepentingan para pelaku gender bending 
Jurnal Ilmu Komunikasi UHO : Jurnal Penelitian Kajian Ilmu Komunikasi dan Informasi.

Volume 6, No. 4, Oktober 2021, hlm 525-547

diberikan dalam adegan ini. Menurut Berger dan Keller, perkawinan bukan sekedar melangkah ke arah peranan baru, tetapi juga langkah ke satu dunia baru. (Jokie M.S. Siahaan, 2009) Dalam perspektif para gay, Siahaan menyebutkan pernikahan melambangkan komitmen dalam suatu hubungan untuk membangun dunia bagi mereka sendiri, tetapi sekaligus sebagai simbol sosial bagi kelompok gay. (Jokie M.S. Siahaan, 2009). Pemaknaan akan pernikahan gay atau sesama jenis sebagai simbol dari kebudayaan baru dalam masyarakat modern Amerika berupaya untuk disampaikan dalam adegan ini, dan membiarkan makna tersebut dikonsumsi oleh pubik sebagai sebuah tatanan baru dalam konstruksi sosial masyarakat modern.

\section{Analisis Paradigmatik Scene Protes Warga}

Analisis kode hermeneutik, pada adegan ini terdapat beberapa tekateki untuk diungkapkan. Pertama, mengapa ada kelompok orang yang marah? Kenapa seorang pria meminum tehnya sambil berjalan dan tersenyum? Dalam adegan ini scene munculnya kelompok protes dari warga muncul setelah scene pernikahan sesama jenis, dan seorang pria yang meminum teh muncul setelah protes warga. Sebagai sebuah satu kesatuan, scene-scene tersebut menunjuk narasai yang slaing berhubungan. Penolakan warga terhadap pernikahan gay merupakan simbol dari kondisi yang sedang terjadi di masyarakat Amerika khususnya saat ini di mana meskipun sudah dilegalkan melalui Mahkamah Konstitusi negara Amerika, pernikahan gay masih mendapat penolakan dari sebagian masyarakat. Kemudian seorang pria yang berjalan dan meminum tehnya sambil berjalan, adalah diperankan oleh seorang gay dari komunitas muslim, Tan France yang menunjukan sikap tidak peduli degan adnaya protes dan berlalu pergi sambil meminum tehnya.

Analisis kode proaretik adalah adanya tindakana penolakan dari kelompok warga terhadap pernikahan gay yang diselenggarakan di lingkungan komunitas gender bending. Aksi berikutnya adalah tindakan meminum teh yang dilakukan oleh cameo Tan France, seorang muslim yang mendeklarasikan dirinya gay.

Kode simbol-simbol dalam leksia ini terdapat beberapa poin menurut peneliti. Pertama, adalah adanya simbol konflik konstruksi sosial budaya liberal pernikahan sesama jenis dengan simbol sistem sosial masyarakat timur dan barat. Seperti dalam penelitiannya, Siahaan menyatakan bahwa konstruksi sosial masyarakat timur sangat mensakralkan pernikahan sebagai bagian dari simbol norma yang ada dalam masyarakat, dengan nilai-nilai adata dan keagamaan yang melekat. (Jokie M.S. Siahaan, 2009) Terdapat juga beberapa 
Jurnal Ilmu Komunikasi UHO : Jurnal Penelitian Kajian Ilmu Komunikasi dan Informasi.

Volume 6, No. 4, Oktober 2021, hlm 525-547

bagian dari kelompok masyarakat di dunia barat yang memberikan arti yang sama dalam pernikahan, sebagai norma sosial yakni menikah dengan lawan jenis. Sementara dalam budaya barat, yang mengarah pada budaya liberal, pernikahan sesama jenis sudah melalui proses internalisasi ke dalam konstruksi sosial masyarakatnya. (Poloma, 2007) Sehingga dalam adegan ini penolakan warga terhadap pernikahan gay merupakan simbolisasi adanya konflik sosial dari masyarakat yang masih berkembang hingga saat ini.

Kode kultural dalam leksia ini, pertama adalah kode budaya dari masyarakat barat yang mendukung eksistensi gender bending yakni pernikahan gay, kemudian adalah budaya penolakan atas norma sosial yang dilanggar oleh kelompok warga yang tidak menerima adanya pernikahan sesama jenis. Selanjutnya kode budaya yang peneliti temukan adalah budaya populer barat yang adegannya diperankan oleh Tan France seorang gay muslim. Tan France adalah guru mode di reality show Queer Eye di Amerika Serikat. Meskipun France bukan berasal dari warga negara Inggris. "teh" dalam bahasa gaul budaya pop mengacu pada gosip panas. (Crummy, 2019) France meminum teh sebagai gosip panas menolak pernikahan gay sebagai simbol tidak peduli terhadap gossip panas dan penolakan tersebut.

Analisis kode semantik ini adalah penolakan internalisasi sistem sosial liberal barat pernikahan gay ke dalam sistem sosial masyarakat pada umumnya. Meskipun terdapat penolakan, seorang gay yang memerankan cameo meminum teh panas sambil berjalan (sebagai simbol dari gossip dalam budaya populer (Crummy, 2019), menunjukan makna sikap yang tidak peduli dengan penolakan tersebut.

\section{Analisis Paradigmatik Scene Penjual Eskrim}

Terkait dengan kode hermeneutik, pada adegan ini terdapat pertanyaan ada apa dengan pria penjual eskrim tersebut? apa hubungannya dengan musik ini? Jawaban dari pertanyaan tersebut adalah diketahui bahwa pria gay penjual eskrim dalam video adalah Bintang skating figur Olimpiade, Adam Rippon. Kemunculan cameo Adam bersamaan dengan lirik "Cause shade never made anybody less gay", yang jika diterjemahkan secara bebas artinya "keteduhan tidak menjadikan seseorang menjadi gay". Lirik ini memiliki hubungan dengan cameo Adam, yang seorang gay dan diintepretasikan bahwa gay adalah pria dengan kelembutan, sekaligus keteduhan atau kesejukan yang erat dengan aktifitasnya sebagai atlit es.

Analisis kode proaretik adalah pengungkapan "keteduhan dari pria bukan berarti dia menjadi gay" dari lirik Taylor yang divisualisasikan oleh cameo penjual eskrim, seorang gay Adam Rippon. Sementara, analisis kode simbolik dalam adegan ini, adalah simbol 
Jurnal Ilmu Komunikasi UHO : Jurnal Penelitian Kajian Ilmu Komunikasi dan Informasi.

Volume 6, No. 4, Oktober 2021, hlm 525-547

"keteduhan" seorang gay yang divisualkan oleh cameo Adam Rippon. Dalam dunia gay, terdapat gay yang disebut Top dan gay yang disebut Bottom. Perbedaannya adalah gay Top lebih cenderung pada sifat laki-laki atau peran gay laki-laki, termasuk dalam hal seksual, sedangkan Bottom lebih cenderung pada gay yang bersikap perempuan atau berperan perempuan, termasuk dalam hal seksual. (Hendra Ardiansyah dan Diyah Utami, 2016)

Pada adegan ini, simbol Adam sebagai seorang gay yang memiliki karakteristik seperti perempuan yang lembut dan teduh. Dalam makna liriknya, Taylor menyinggung para pria yang membenci gay dengan menggunakan frasa satir keteduhan seorang pria tidak menjadikan mereka seorang gay.

Kode kultural dalam latar adegan ini adalah latar budaya barat dimana seorang pria gay yang tidak ragu-ragu untuk menunjukan keberadaan dan identitasnya dalam masyarakat dengan menjadi seorang penjual eskrim. Seorang gay dalam adegan ini sudah melebur dalam sosialisasi dengan masyarakat, yang tidak ragu untuk menunjukan dirinya dengan penampilan yang identik degan aktualisasi dan simbol seorang gay.

Analisis kode semnatik dalam adegan ini adalah makna keteduhan dari seorang gay bottom yang diperankan oleh Adam. Makna tersebut disampaikan oleh taylor dalam lagunya yang secara satir menyinggung para pembenci gay. Pemaknaan lirik menjadi atribut yang penting dalam analisis semiotika. (Sobur, 2001) Melalui analisis teks, maka akan ditemukan intepretasi tersembunyi yang dalam analisis hermeneutik makna teks akan menjelaskan makna tersembunyi. Swift berupaya untuk mengumumkan bagian penting dari kampanyenye mengenai gay, bahwa menjadi seorang gay tidak melulu tentang seksualitas, tetapi juga keteduhan yang dapat membawa dunia menjadi damai. Demikian menurut pemaknaan peneliti terhadap leksia tersebut.

\section{Analisis Paradigmatik Scene "Pop Queen Pageant"}

Terkait dengan kode hermeneutik, pada adegan ini terdapat beberapa pertanyaan, mengapa ada kontes ratu pop? Kenapa semua transgender menirukan (cosplay) diri mereka dengan penyanyi pop? Jawaban dari teka-teki tersebut, adegan kontes kecantikan dimana para pelaku gender bending adalah bagian dari kampanye transgender menurut peneliti. Hal ini tidak terlepas dari kemunculan Laverne Cox, yang dikenal karena aktivisnya untuk hak-hak transgender. Kemudian pemilihan cosplay beyonce secara khusus yang sebagai simbol dari pendukung hak-hak transgender dan LGBT. 
Jurnal Ilmu Komunikasi UHO : Jurnal Penelitian Kajian Ilmu Komunikasi dan Informasi.

Volume 6, No. 4, Oktober 2021, hlm 525-547

Analisis kode proaretik dalam adegan ini adalah kegiatan kontes ratu pop bagi para transgender yang dibuat untuk memberikan panggung untuk para transgender yang berperan sebagai cameo dalam video tersebut. Dimana para cameo adegan ini adalah Jajaran mantan kontestan Drag Race dan peniru Beyoncé yang terkenal.

Kode simbol dalam adegan ini adalah simbol budaya dari populer dimana kontes pencarian bakat merupakan simbol dari produksi dan konsumsi budaya populer. Menurut Theodor Adorno, seorang alumni mahzab Frankfurt, produksi dan konsumsi budaya dalam masyarakat kapitalis sudah 'terstandardisasi.' (Rizki Kurniawan, 2014) Kontes pencarian bakat, menurutnya dalam hal ini, juga merupakan produksi dalam budaya populer untuk menciptakan popularitas.

Dari latar budaya yang muncul dalam leksia ini, kode kurtural dalam adegan adalah latar dari budaya populer barat Amerika. Hal ini sebagaimana Adorno jelaskan bahwa budaya populer barat yang divisualisasikan dalam budaya masyarakat modern adalah gelaran acara pencarian bakat, cosplay atau menirukan artis tertentu, yang kesemuanya diterima oleh masyarakat barat dan dikomsumsi sebagai bagian dari hiburan dalam televisi. (Rizki Kurniawan, 2014)

Analisis kode semantik dalam kontes ratu kecantikan dalam video ini, terdapat beberapa makna yang peneliti ajukan. Pertama, adalahnya penggambaran simbol-simbol gerakan gender bending yang diperankan oleh para cameo Drag Race, menunjukan betapa kuatnya dukungan dari para penyanyi pop di Amerika terhadap gerakan kesetaraan dan gender bending. Kedua, bentuk kegiatan kontes ratu pop juga memberikan makan tersendiri bagi penonton untuk memahami bagaimana kontes kecantikan dan berbagai lainnya adalah manifestasi dari budaya pop yang saat ini sudah berkembang di Amerika khususnya.

7. Analisis Paradigmatik Scene Pelemparan Mahkota

Terkait dengan kode hermeneutik, pada adegan ini terdapat beberapa pertanyaan, siapa orang yang tiba-tiba muncul membawa mahkota? Kenapa mahkota kontes tidak diberikan malah dilempar ke udara? Adegan ini menampilkan kelanjutan dari scene sebelumnya dimana jajaran mantan kontestan Drag Race dan peniru Beyoncé yang terkenal berpartisipasi dalam "kontes ratu pop", kemudian muncul cameo juri kontes, Rupaul, yang alih-alih memberikan mahkota kontes hanya kepada salah satu kontestan, RuPaul muncul di atas panggung dan kemudian melemparkannya ke udara. Sepertinya semua ratu pop dimaksudkan untuk berbagi mahkota. Pelemparan mahkota ke udara, menurut temuan peneliti mirip dengan adegan yang sama dalam film populer di Amerika Mean Girls, yang 
Jurnal Ilmu Komunikasi UHO : Jurnal Penelitian Kajian Ilmu Komunikasi dan Informasi.

Volume 6, No. 4, Oktober 2021, hlm 525-547

merupakan film komedi remaja wanita populer tahun 2004. Plot film menceritakan kisah gadis yang memiliki sifat jahat, akan tetapi akhirnya ia sadar, dan ketika ia memenangkan sebuah mahkota dalam pemilihan ratu tarian spring fling. alih-alih menerima mahkota untuk dirinya sendiri, dia malah membagikannya kepada teman-temannya.(Wiseman, 2004).

Analisis kode proaretik dalam adegan ini adalah adanya aksi melemparkan mahkota yang dilakukan oleh cameo RuPaul. Tindakan tersebut ia lakukan untuk memberikan simbol satir tidak adanya persaingan memperbutkan ratu dalam dunia gender bending.

Kode simbolik dari adegan ini adalah simbol transgender yang begitu melekat yang ditampilkan oleh para peserta kontes, melalui gaya berpakaian, asesoris hingga atribut dan bahasa tubuh yang mereka gunakan. Kemudian simbol yang kedua adalah simbol budaya popbarat yang divisualisasikan melalui acara kontes ratu pop.

Berdasarkan pada latar yang ada dalam adegan, kode kultural yang terdapat dalam leksia ini adalah kode kultural budaya popular barat. Dimana pemilihan scene adegan kontes pemilihan ratu pop yang diperankan langsung oleh para anggota Drag Race dan drag queen RuPaul yang disebut-sebut oleh media Amerika sebagai waria paling sukses sevara komersil. Kehadiran para cameo tersebut secara kultural menunjukan budaya populer barat Amerika yang divisualisasikan dalam adegan video.

Analisis kode semantik dalam dua bentuk adegan. Pertama, makna dukungan yang kuat dari para selebritas dan penyanyi pop barat Amerika yang diperankan cosplay nya oleh para Drag Race atau waria. Kedua, makna internalisasi budaya populer yang ditonjolkan oleh Taylor melalui scene kontes ratu pop. Taylor swift yang merupakan ikon pop Amerika, menunjukan bagaimana hegemoni Amerika Serikat dalam dunia hiburan dan pembentukan budaya global ini dapat dikatakan sebagai satu bentuk penyebaran budaya kultural Amerika yang dalam leksia ini ditunjukan dengan acara kontes ratu pop oleh para waria.

8. Analisis Paradigmatik Scene Lukisan

Terkait dengan kode hermeneutik, pada adegan ini terdapat beberapa pertanyaan, siapa orang yang sedang melukis itu? Apa yang dia lukis? Apa hubungan lukisan dengan video musik? Teka-teki dari pertanyaan tersbeut akan ditemukan ketika scene (secara terpisah) pada leksia berikutnya kemunculan kredit titel yang berisikan petisi yang dibuat oleh Taylor untuk mendukung regulasi hak politik bagi kalangan LGBT dalam konstitusi Amerika Serikat. Foto Stonewall Inn yang sedang dilukis oleh cameo yang diperankan Aktor Deadpool, Ryan Reynolds. Bagi aktivis dan pelaku gender bending, Stonewall Inn merupakan sejarah yang tidak akan pernah dilupakan. Karena lokasi tersebut, adalah simbol 
Jurnal Ilmu Komunikasi UHO : Jurnal Penelitian Kajian Ilmu Komunikasi dan Informasi.

Volume 6, No. 4, Oktober 2021, hlm 525-547

sejarah kerusuhan Stonewall. Serangkaian demonstrasi spontan dengan kekerasan oleh anggota komunitas gay memprotes penggerebekan polisi yang terjadi pada dini hari 28 Juni 1969 di Stonewall Inn, kawasan Greenwich Village, New York City.

Analisis kode proaretik adalah aksi perjuangan kaum gay yang disimbolisasikan melalui adegan melukis lokasi bersejarah bagi kaum gay Amerika yakni Stonewall Inn. Kemudian memiliki kaitan dengan leksia berikutnya yakni petisi yang dibuat Taylor sebagai aksi untuk mendukung legalisasi hak politik kaum LGBT di Amerika.

Kode simbolik dalam leksia ini adalah foto Stonewall Inn yang sedang dilukis oleh cameo aktor Deadpool, Ryan Reynolds. Stonewall Inn merupakan simbol sejarah dalam perjuangan kesetaran hak kaum gay di Amerika. Melansir dari situs thestonewallinnnyc.com, Serangkaian demonstrasi spontan dengan kekerasan oleh anggota komunitas gay dilakukan pada Stonewall yang memprotes penggerebekan polisi pada komunitas gay yang terjadi pada dini hari 28 Juni 1969 di Stonewall Inn, kawasan Greenwich Village, New York City.

Kode kultural dalam adegan ini adalah budaya popular Amerika yang mengambil tema sejarah gerakan perjuangan kaum gay Amerika. Meskipun hanya berdurasi singkat, namun kemunculan simbol Stonewall Inn merupakan bagian dari kebudayan dalam aktivitas gender bending di Amerika.

Analisis kode semantik dalam adegan ini adalah makna sejarah bagi gender bending, yang divisualisasikan melalui kemunculan foto Stonewall Inn. Makna sejarah bagi perjalanan perjuangan kalangan gay dan gender bending di Amerika Serikat, berupaya untuk disampaikan oleh Taylor dalam leksia ini. Kemudian scene credit title petisi dukungan bagi LGBT di Amerika memiliki makna khusus mengenai pembuatan video yang di dedikasikan secara khusus oleh Taylor untuk kelompok LGBT dan gender bending.

\section{SIMPULAN}

Berdasarkan pembahasan hasil penelitian, representasi gender bending pada musik video You Need to Calm Down dari Taylor Swift nampak pada level realitas dan level ideologi. Pertama, gender bending sebagai sebuah realitas dan ideologi, digambarkan melalui berbagai kode dalam adegan-adegan video. Kedua, representasi gender bending sebagai sebuah simbol budaya popular yang digambarkan melalui fashion, ide, sikap, bahasa dan perilaku dalam adegan-adegan video. Konsepsi sistem sosial dan kultural yang ditampilkan dalam video, menggambarkan budaya popular yang akan berkembang di dunia dengan 
Jurnal Ilmu Komunikasi UHO : Jurnal Penelitian Kajian Ilmu Komunikasi dan Informasi.

Volume 6, No. 4, Oktober 2021, hlm 525-547

tatanan dunia yang berdampingan dengan para kelompok yang menolak gender tunggal atau gender bending. Ketiga, berdasarkan hasil analisis kode Roland Barthes, beberapa teka-teki yang muncul dalam berbagai leksia video seperti kutipan seorang feminis, lukisan foto Stonewall Inn, merupakan beberapa leksia yang merepresentasikan gender bending sebagai bagian dari gerakan feminisme liberal yang mendobrak gagasan gender yang dianggap konvensional. Kode simbolik terdapat dalam kemunculan ikon transgender, serta beberapa simbol dari dukungan terhadap gerakan gender bending. Pada tataran kultural, adanya adegan-adegan perilaku masyarakat barat seperti pemukiman komunitas LGBT, pernikahan sesama jenis, penggunaan bahasa gaul, hingga adegan kontes ratu pop, menggambarkan bagaimana melalui musik video You Need To Calm Down representasi gender bending sebagai simbol dalam budaya populer. 
Jurnal Ilmu Komunikasi UHO : Jurnal Penelitian Kajian Ilmu Komunikasi dan Informasi.

Volume 6, No. 4, Oktober 2021, hlm 525-547

\section{DAFTAR PUSTAKA}

Adamson, B. (2008). Freedom of Religion, the First Amendment, and the Supreme Court: How the Court Flunked History. Pelican Publishing.

Adryamarthanino, V. (2020). Lirik dan Chord Lagu You Need To Calm Down dari Taylor Swift. Kompas.Com. Retrieved from https://www.kompas.com/hype/read/2020/10/06/131500466/lirikdan-chord-lagu-you-need-to-calm-down-dari-taylor-swift?page=all

Ari Setyorini(. (2011). Performativitas Gender Dan Seksualitas Dalam Weblog Lesbian Di Indonesia. Kawistara, 1 No. 2, 103-212.

Bambang Mudjiyanto, E. N. (2013). analisis semiotika Roland Barthes bertujuan untuk menyediakan metode analisis dan kerangka berpikir untuk menghindari terjadinya misreading atau kesalahan pembacaan atas makna suatu tanda. Prinsip dari semiotika dalah pemaknaan dan penafsiran atas tanda. Penelitian Komunikasi, Informatika Dan Media Massa (Pekommas), 16 No. 1.

Brillian Barro Vither. (2015). Interpretasi Khalayak Terhadap Pemberitaan Kasus Kekerasan Seksual Di Jakarta International School Di Televisi. Universitas Diponegoro, Semarang.

Chasanah, I. (2017). Representasi Hedonisme Dalam Film Pendek "Berbie" Sutradara Rembulan Sekar Jati. Almamater Wartawan Surabaya.

Crummy, C. (2019). Queer Eye's Tan France: "The Word Gay Was Never Mentioned In My Parents" Home"." The Guardian. Retrieved from https://www.theguardian.com/lifeandstyle/2019/mar/09/queer-eye-tan-france-the-word-gay-wasnever-mentioned-in-my-parents-home

Damaledo, Y. D. (2019). Dukung LGBT, Taylor Swift Rilis Video "For You Need To Calm Down." Tirto.ID. Retrieved from https://tirto.id/dukung-lgbt-taylor-swift-rilis-video-for-you-need-tocalm-down-ecBS

Dese, T. A. (2013). Representasi Pesan LGBT dalam Video Musik Popular "Born This Way" dan "If I Had You." E-Komunikasi, 1 No. 1.

Douglas Kellner. (2010). Budaya Media: Antara Modern Dan Postmodern. Yogyakarta: Jalasutra.

Hanif, M. (2011). Studdi Media Dan Budaya Popular Dalam Perspektif Modern Dan Postmodernisme. Junal Dakwah \& Komunikasi, 5 No. 2.

Haryati, H. (2012). Konstruktivisme Bias Gender Onstruktivisme Dalam Media Massa. Observasi, 10 No. 1 .

Hendra Ardiansyah dan Diyah Utami. (2016). Dramaturgi Mencari Pasangan Pada Kaum Homoseksual (Gay). Paradigma, 04 No. 01.

Indana Laazulva, Yuli Rustinawati, C. A. (2013). Menguak stigma, kekerasan \& diskriminasi pada LGBT di Indonesia: studi kasus di Jakarta, Yogyakarta, dan Makassar : pembahasan khusus fenomena trans/homophobic bullying pada LGBT. Jakarta: King Oey: Arus Pelangi.

Jokie M.S. Siahaan. (2009). Perilaku Menyimpang: Perilaku Menyimpang Pendekatan Sosiologi. Jakarta: PT. Indeks.

Lubis, S. (2006). Gerakan Feminisme dalam Era Postmodernisme Abad 21. Demokrasi, V No. 1.

Moller, D. (2011). Redifining Music Video. California: Major Written Assessment.

Muslim, H. (2021). Analisis Semiotika Lirik Dan Visual Video Klip Musik "Lathi" Oleh Genius Featuring Sara Fajrina. Universitas Sumatra Utara, Medan.

Piliang, Y. A. (2012). Semiotika dan Hipersemiotika: Gaya, Kode dan. Matinya Makna. Bandung: Matahari.

Poloma, M. M. (2007). Sosiologi Kontemporer (Yasogama, Ed.). Jakarta: Raja Grafindo.

Rizki Kurniawan. (2014). Imitasi Budaya Pada Tayangan Televisi Di Indonesia. Dimensi Seni Rupa Dan Desain, 11 No. 2.

Samudro, A. (2019). Taylor Swift Rilis Lagu You Need to Calm Down \& Rencana Album Lover. Tirto.ID. Retrieved from https://tirto.id/taylor-swift-rilis-lagu-you-need-to-calm-down-rencanaalbum-lover-ecpV

Sobur, A. (2001). Analisis Teks Media: Suatu Pengantar untuk Analisis Wacana, Analisis Semiotik, dan Analisis Framing. Bandung: PT Remaja Rosdakarya.

Sobur, A. (2013). Filsafat Komunikasi. Bandung: PT Remaja Rosdakarya.

Strinati, D. (2010). POPULAR CULTURE - Pengantar Menuju Teori Budaya Populer. Yogyakarta: 
Jurnal Ilmu Komunikasi UHO : Jurnal Penelitian Kajian Ilmu Komunikasi dan Informasi. Volume 6, No. 4, Oktober 2021, hlm 525-547

Bentang of Communication.

Wiseman, $\quad$ R. (2004). Mean Girls. Retrieved from https://www.imdb.com/title/tt0377092/?ref_=fn_al_tt_1 